Review Article

\title{
Diet and Nutrition in the Prevention of Non-Communicable Diseases
}

\author{
KAMALA KRISHNASWAMY ${ }^{1, *}$, RUCHI VAIDYA ${ }^{2}$, GAYATHRI RAJGOPAL ${ }^{2}$ and SUDHA \\ VASUDEVAN ${ }^{2}$ \\ ${ }^{1}$ Former Director, National Institute of Nutrition, Hyderabad; Senior Honorary Advisor, Madras Diabetes \\ Research Foundation, Chennai, India \\ ${ }^{2}$ Department of Foods, Nutrition and Dietetics Research, Madras Diabetes Research Foundation, Chennai, \\ India
}

(Received on 30 April 2016; Accepted on 03 May 2016)

\begin{abstract}
Worldwide non-communicable diseases (NCDs) occur due to multiple etiological factors impacting development and economic progress. Developing countries have dual burden of diseases viz., under and over nutrition, which are critical public health challenges. NCDs occur a decade earlier in India. Changing economic scenario, evolving agriculture practices, rapid strides in industrialization, migration, urbanization, globalization and trade liberalization impact the food environment. The resulting dietary transitions lead to replacement of whole/coarse grains/grams with refined foods. Availability, affordability and accessibility of energy- dense foods with excess unhealthy fat, sugar, salt and animal foods, have replaced traditional foods. The intake of healthy horticulture produce such as vegetables, fruits, legumes/pulses, nuts, seeds and fish are inadequate. Broad diversified dietary patterns rather than single foods/nutrients have healthy outcomes. Excess alcohol and tobacco add to the insults. Physical activity has reduced in all segments of the population and domains of physical activity. These steering dynamics change the lifestyles leading to obesity and shifting disease patterns which have overwhelming effects on human capital and the health system. Proactive prevention with comprehensive policies cutting across several risk factors with consensus from all stake holders including the private segment is essential to tide over the crisis. The WHO has committed to reduce under-nutrition, obesity and diet-related NCDs, monitor policy response and catalyse effective actions to achieve specified targets by 2025. The national governments must create the enabling environment to achieve the same. India has initiated action-oriented program for risk reduction with the Health Ministry as the nodal agent for NCD prevention and control.
\end{abstract}

Keywords: Non Communicable Diseases; Dietary/Nutrition Transition; Physical Activity; Diabetes; Cardiovascular Diseases; Cancer

\section{Introduction}

Worldwide, Non Communicable Diseases (NCDs) are of great public health significance and associated with very high mortality and morbidity impacting human capital and economy. Though, the pharmaceutical industries have several curative and palliative measures to quench the rising epidemic, the health outcomes are not very significant. It is obvious therefore that these diseases of public health concerns need better preventive strategies supported by policies and programs. These diseases affect populations in developing countries a decade earlier. According to the Director General of WHO, "The world has reached a decisive point in the history of NCDs and has an unprecedented opportunity to alter its course" (WHO, 2013). Demographic, socioeconomic aspects, technological innovations, migration, rapid urbanization, globalization, dietary/ nutrition transition, motorized transport, physical inactivity, stress and personal habits/alcohol consumption and use of tobacco are the major drivers of epidemiological transition leading to obesity (higher body fat) and NCDs.

Developing countries such as India primarily concentrate on under-nutrition and rightly so, but can no longer neglect diseases due to over-nutrition.

*Author for Correspondence: E-mail: sri21kk@yahoo.com 
Developmental origins of adult diseases due to foetal malnutrition and programming are well documented as risk factor for NCDs in adults (Barker, 1998) and have trans-generational effects. A higher intake of energy- dense foods, refined and fatty foods, processed/convenience and animal foods, salty and sugary snacks, low intake of whole grains, vegetables, fruits and nuts coupled with physical inactivity result in NCDs. Hence, prevention strategies as public health measures must have applicable and realistic goals for these challenging issues. We need to seize this opportunity to act on time. This article encapsulates the current determinants of NCDs and presents dietary strategies for prevention of diabetes, cardiovascular diseases (CVD) and cancer. Both global and Indian scenario is portrayed.

\section{Burden of Non-communicable Diseases (NCDs)}

In 2012, mortality worldwide due to NCDs was higher than due to communicable diseases-maternal, neonatal, and nutritional disorders (Fig. 1A). CVD, diabetes, cancer and respiratory diseases were the most common causes of death. Almost 16 million deaths due to NCDs were premature and $82 \%$ of these premature deaths occurred in the developing world (low-middle income countries-LMIC).

In parallel with global mortality rates, NCDs accounted almost for two third $(60 \%)$ deaths in India in 2012(Fig.1A). Deaths due to NCDs both in the world and India are given in Fig. 1B (WHO, 2014 \& WHO 2014a). About $12 \%$ of heart attacks in India occur a decade earlier ( $<40$ years of age) than the world's average age of 50 years (WHO 2014). India has dual burden of diseases at both ends of nutrition spectrum, one telescoping into other, compelling strategies to address both groups of disorders (Marshell, 2004).

The deaths are due to superimposed poor health behaviours mainly tobacco usage, unhealthy diet, physical inactivity and alcohol consumption. Smoking is estimated to cause about $71 \%$ of all lung cancer deaths, and nearly $10 \%$ of CVD (WHO, 2010). About $1 \%$ of disability adjusted life years (DALYs) and $2.8 \%$ of mortality globally are due to low fruit and vegetable consumption (WHO, 2003) while $5.7 \%$ of deaths and $2.1 \%$ of global DALYs are attributable to physical inactivity. In India 15\% of deaths are due to tobacco, $4.3 \%$ due to alcohol, $1.9 \%$ due to overweight/obesity and $21.1 \%$ due to high blood pressure (WHO, 2014). It therefore warrants the attention of policy makers, public health scientists, clinicians as well as civic societies.

\section{Economic Burden of NCDs}

NCDs are reported as the major global threat to economic development particularly in LMIC due to increased morbidity, mortality, decreased quality of life and life expectancy. An average economic loss of nearly US $\$ 500$ billion per year (2011-2025) is estimated from the 4 diseases (diabetes, CVD, cancer and chronic obstructive pulmonary disease (COPD)) in LMICs (WHO, 2010).

Bloom et al. (2011) have calculated the economic burden of NCDs in India viz. type 2 diabetes, CVD, COPD, cancer and mental health between 2012-2030 to be US $\$ 4.58$ trillion loss due to reduced savings, reallocation for treatment, and inevitable loss of productivity of sick or dead workers. Thakur et al. (2011) reported the cost of NCDs is about $5-10 \%$ of GDP in India .NCDs enhance the household medical expenditure (Patel et al., 2011).

Reduction of economic growth by $0.5 \%$ was observed for every $10 \%$ increase in mortality due to NCDs (Abegtunde and Stanciole, 2006).

\section{Non-Dietary Determinants of NCDs}

Among the major non-dietary determinants of NCD are: demographic transition, globalisation, trade liberalisation, industrialisation, socio economic factors, migration \& urbanisation. Rapid demographic transition is occurring in developing world without the social changes such as improved living conditions, better nutrition, income growth and better access to public health services that occurred in most developed countries decades ago (Engelgau, 2011). In India thanks to improved health care, the crude birth, death and infant mortality rates have registered a significant decline from 1971 to 2013 (Census 2013) with consequent increase in economically active $(63.3 \%)$ and elderly population $(8.3 \%)$. Yet NCD-related DALYs are alarmingly high in the early ages and it would be best to invest in this prime age group and proactively prevent NCDs.

Globalization refers to an increased flow of finances, traded goods and migration of people and 


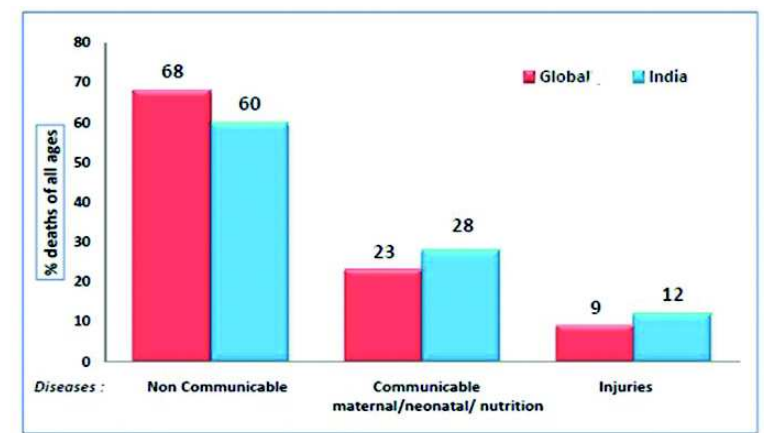

(A)

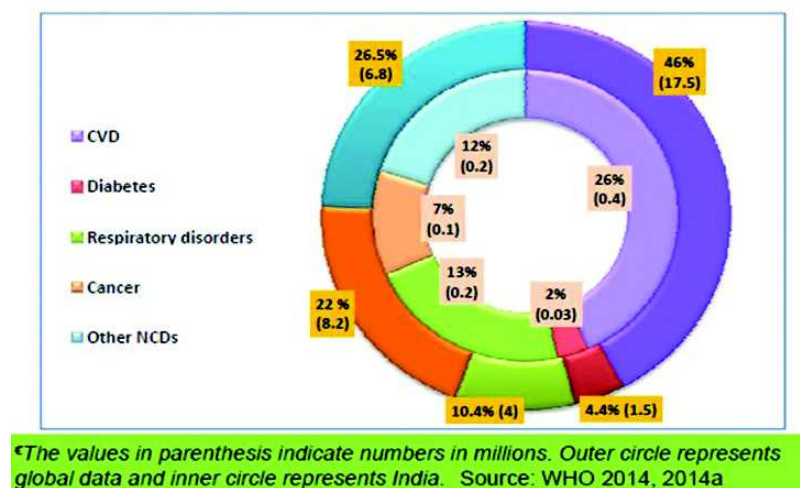

(B)

Fig. 1: (A) Causes of mortality, (B) Mortality due to noncommunicable diseases

new concepts resulting in economic, political and social interdependence (Shetty, 2003). The global value of food trade has gone up enormously (18\%) with export of foods becoming twice $(6 \%)$ that of non food items (3\%) (International Trade Statistics, 2015).

When agriculture was introduced into global trade, all aspects of food production and processing transformed agro-food industries into large multinational corporations with powerful marketing strategies. The economic liberalisation policies and foreign direct investment enhanced food processing (FAO, 2004; WHO, 2007). The economic growth in Asian countries resulted in higher consumption of unhealthy foods due to aggressive sales at affordable costs. These are the global catalysts of the growing epidemic of NCDs (Stuckler et al., 2012). The GDP growth rate in India is $7.5 \%$ in 2015-2016. A total of $43 \%$ in urban and $53 \%$ in rural monthly consumption expenditure was on food and beverages in the year 2013-14 in India as against 9\% in USA (Credit Suisse, 2015).

Even though economic growth is impressive in developing countries, disparities between and within countries exists. Low birth weight due to in utero under-nutrition in low-income population increases the vulnerability to NCDs mainly obesity, type 2 diabetes and CVD (Yajnik, 2004). In India, prevalence of hypertension was found to be statistically similar in selected communities of all socio-economic status (SES) groups (Xaviers et al., 2008). A multi centric study of 50 cities in India reported that death rate due to CVD was significantly high in low SES group (8.2\%) compared to high SES group $(5.5 \%)$ (Subramanian et al., 2013). These signify that India needs to revise the health care policies for universal access with equitable distribution.

Almost $32 \%$ of the Indian populations are urbanites (World Bank report, 2014). The speed of urban growth has led to innumerable lifestyles and social changes that have a remarkable effect on disease patterns. According to NSSO (2010), 35\% of India's urban population constitutes rural migrants, mostly in search of employment and education. This has indirectly impacted home cooked foods. Many prefer cheap and quick meal options of street foods, which are unhygienic, unhealthy- high in salt, fat and sugar (WHO 2010).

\section{Behavioural Risks}

Among the major behavioural risk factors are: Physical inactivity in adults as well as children, alcohol consumption, smoking and use of tobacco; and diet and nutrition transition. Physical inactivity has been identified as the fourth leading risk factor for global mortality (6\%-WHO, 2010). Studies conducted in 122 countries covering almost $89 \%$ of population, indicated $31 \%$ of adults are inactive (Hallal et al., 2012). Promotion of Physical activity (PA) appears to be similar to prevention of smoking or obesity on NCD mortality rates (Swaminathan et al., 2013) as PA has several metabolic health benefits (Fig. 2Warburton et al., 2006) However, the present discussion will be confined to diet and nutrition transition due to constraint of space.

\section{Diet and Nutrition Transition}

Globally diet/nutrition transition has accelerated all chronic diseases and currently developing countries are going through the same phenomenon (Shetty, 2003; Popkin et al., 2012). The green revolution in India (1970) changed the nutrition scenario from 


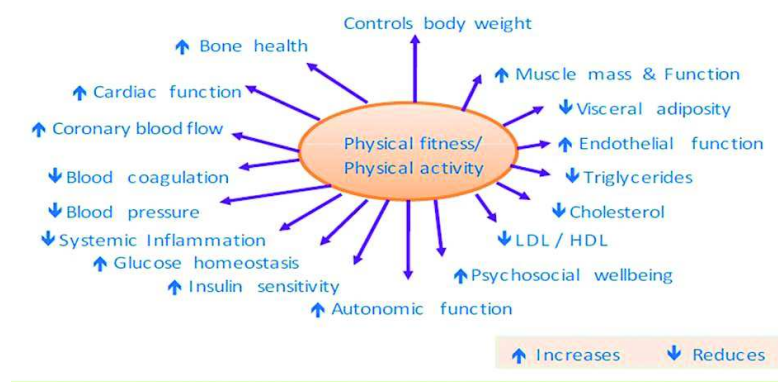

Physical activity positively impacts obesity, CVD, Diabetes, Osteoporosis, Osteoarthritis, Blood pressure, Cancer(Colon \& breast) and depression

Source: Warburton et al, 2006

Fig. 2: Metabolic health benefits of physical activity

hunger and famine to food surplus and export. However, income inequality in India is still persisting with consumption among the poorest being qualitatively and quantitatively poor while the wealthiest produce and consume more. Due to changes in food availability and accessibility, consumption of relatively unhealthy processed and packaged foods, rich in refined grains, oils, salt and sugar has increased. Consumption of whole grains, nuts, fruits and vegetables has not registered significant increase (Radhika et al., 2009, 2011; Ramachandran, 2011; Misra et al., 2011; Kapil and Sachdev, 2012).

A recent analysis of changing food consumption pattern in India (National Council of applied economic research, 2014), data from National Sample Survey organization (NSSO, 2014) and NNMB (2012) show that over the years cereal consumption has declined markedly with attrition of millets. Consumption of protective foods such as pulses, milk, vegetables (except starchy potato) and fruits which are sources of proteins (pulses), fiber and micro/phytonutrients (vegetables) continues to be low. All of them impact glycaemic index (GI) (Fig. 3). Though consumption of animal foods are low milk, fish and poultry have shown improvements but that of mutton declined. However none of these databases capture foods consumed outside the home environment, which can add to refined foods, sugar, salt and fat intake.

While the consumption of energy, carbohydrates and proteins has declined, that of fat has gone up marginally (Fig. 4). The diets in general continue to be qualitatively markedly deficient in micronutrients, particularly vitamins A, B2 (riboflavin), folic acid iron and calcium. Estimates of Vit.B6 and zinc intake are not available. Deficiencies of vitamins such as Folic acid, B12 and B6 can result in elevated homocysteine, a vascular damaging amino acid. Vitamin D deficiency is now recognised as a public health problem which may impact negatively glycaemic control.

\section{Refined Grains}

The visible change in dietary ingestion of the populations across the globe is a shift towards refined carbohydrates (polished rice and refined wheat flour) and processed refined cereals replacing coarse grains (Hu, 2011; Anand et al., 2015; Reddy, 2002). Refining retains starchy endosperm with loss of bran, germ and key nutrients (Shobana et al., 2011). The loss of bran and pulverization of the endosperm aids in rapid digestion and absorption of carbohydrates from refined grains than whole-grain products increasing blood glucose and insulin concentrations ( $\mathrm{Hu}, 2003)$. Thus the staples consumed in today's world are refined, containing only the starchy endosperm with glycaemic carbohydrates strongly associated with obesity and chronic diseases.

\section{Sugar and Sugar-sweetened Beverages (SSB)}

Over the last 50 year the consumption of sugar across the world has almost tripled (Lustig et al., 2012). SSB and other energetic beverages have increased to about $17-25 \%$ of total energy intake in all age groups (Popkin et al., 2010). SSB industry is third largest industry in India after biscuits and tea. SSBs and total sugar intake is high (traditional $+\mathrm{SSB}$ ) among Indians (25kg/capita/annum) compared to worldwide consumption (23.7kg/capita/annum) (Gulati and Misra, 2014). The sales of SSB have increased in India by more than $10 \%$ annually since 1998 and have exceeded 11 litres/capita/year (FoodnavigatorUSA.com, 2011). This may be due to aggressive marketing and sales of SSB despite the efforts made by medical experts and health organizations to limit the consumption of sugar (Taylor et al., 2011; Basu et al., 2013).

\section{Edible Oils and Fats}

Visible fats and oils provide almost half of fat calories in an average Indian diet (Ghafoorunissa, 2007). Data from FAO suggest a rise in the percentage of dietary energy supply from fats (14-19\%) and vegetable oils 

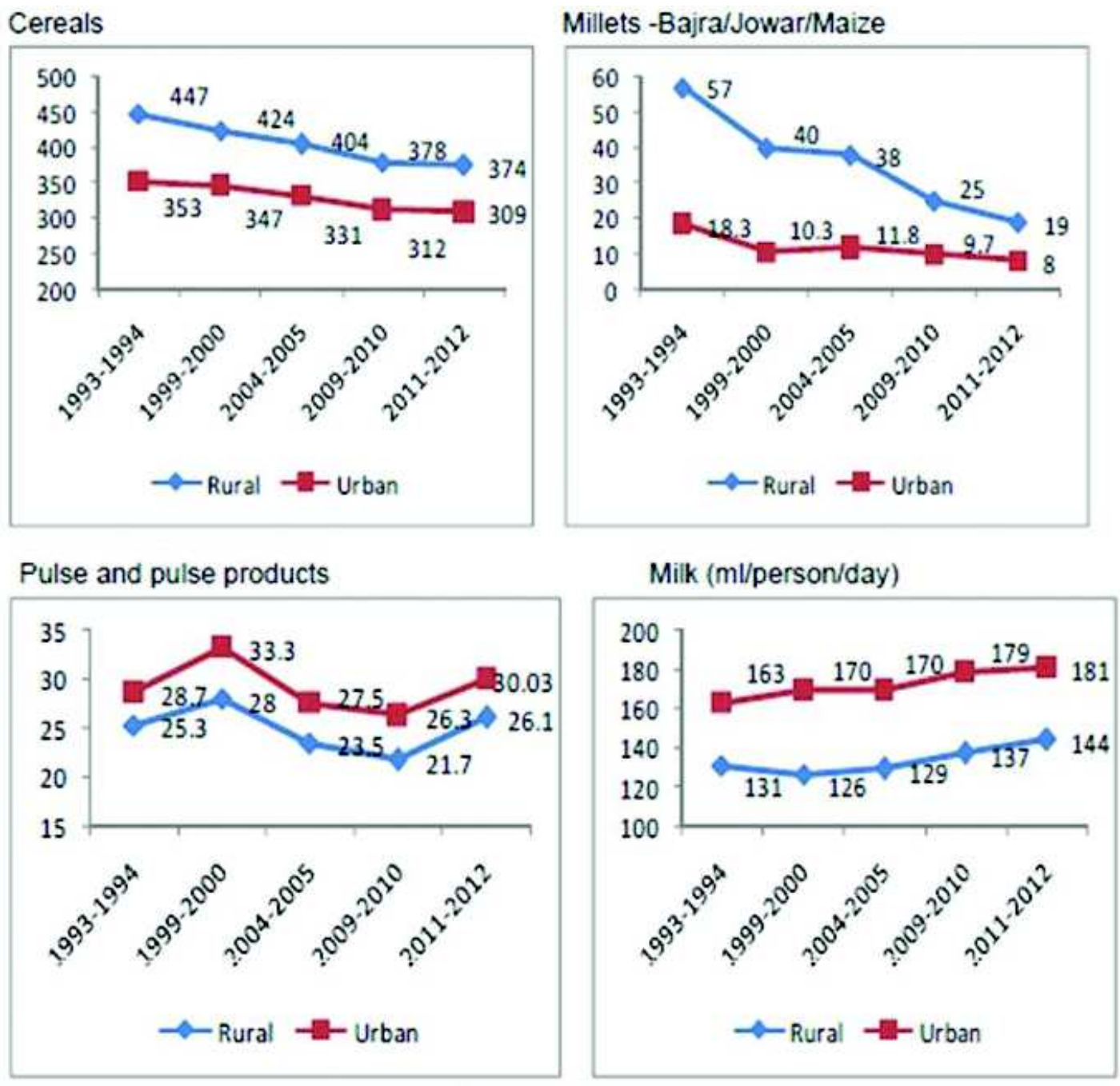

Source: NSSO $68^{\text {th }}$ round, 2014

Figs. 3: Trends in foods and nutrient consumption

(6-10\%) in India from 1980 to 2000 (FAO, 2004; WHO/FAO, 2003).

In addition to cooking oil, ghee (clarified butter), vanaspati (hydrogenated oils) and butter are the source of dietary fat among South Asians. In India ghee and vanaspati (latter rich in trans fatty acidsTFA) are also used as bakery shortening and in the preparation of commercially fried, processed, baked, ready-to eat foods, and street foods (Anand et al., 2015). Joint WHO/FAO report 2003 recommends the TFAs intake to be limited to $<1 \%$ of total daily energy. A study among adolescent and young adults in north India reported the TFAs intake $(\% \mathrm{E})$ to be 1.11 and 1.13 respectively (Misra et al., 2009). Vanaspati and bakery shortenings can contain as high as $50 \%$ trans fat (L'Abbe et al., 2009). Food Safety Standards Authority of India (FSSAI, 2010) recommended TFA content in Vanaspati, to be reduced to $5 \%$ by 2013 and made it mandatory to specify the amount of TFAs on the label of all food products.

\section{Animal Foods}

The increase in the production and consumption of animal foods including milk and meat are primarily contributed by developing countries of the World (Kearney, 2010). By 2020, developing countries will produce $63 \%$ of meat and $50 \%$ of milk and will consume about 107 million metric tonnes (MMT) meat and 177 MMT milk. In India almost 60\% are nonvegetarians (The Hindu, 2006). 


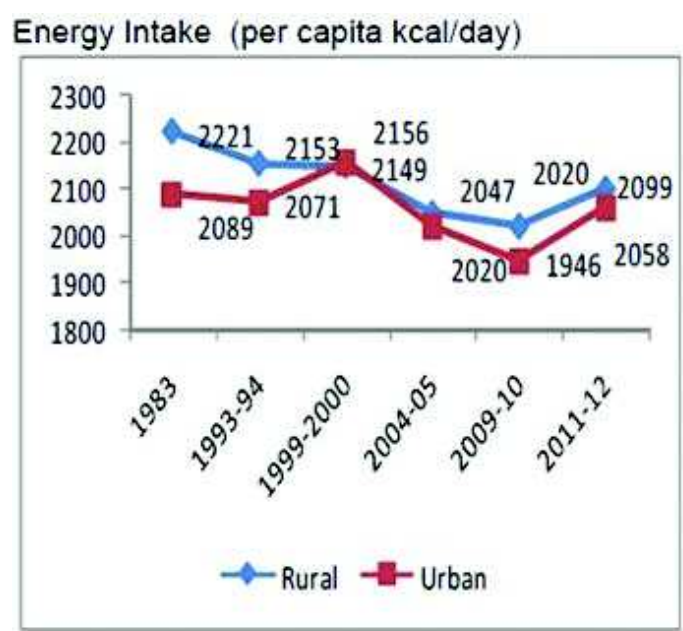

Protein intake (per capita g/day)

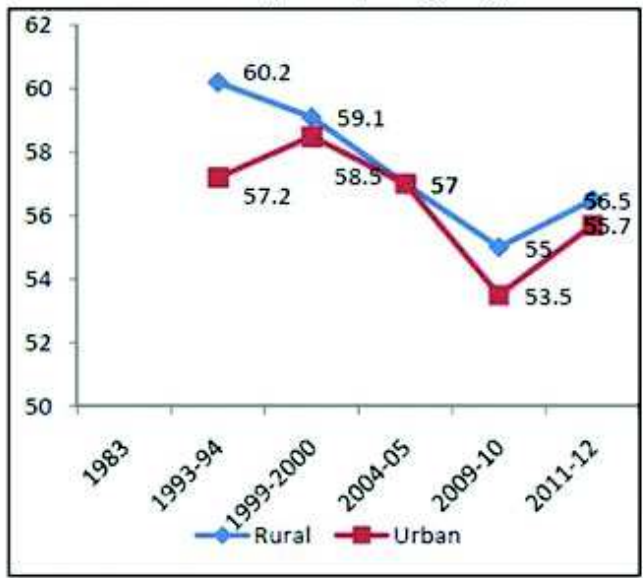

Fat Intake (per capita g/day)

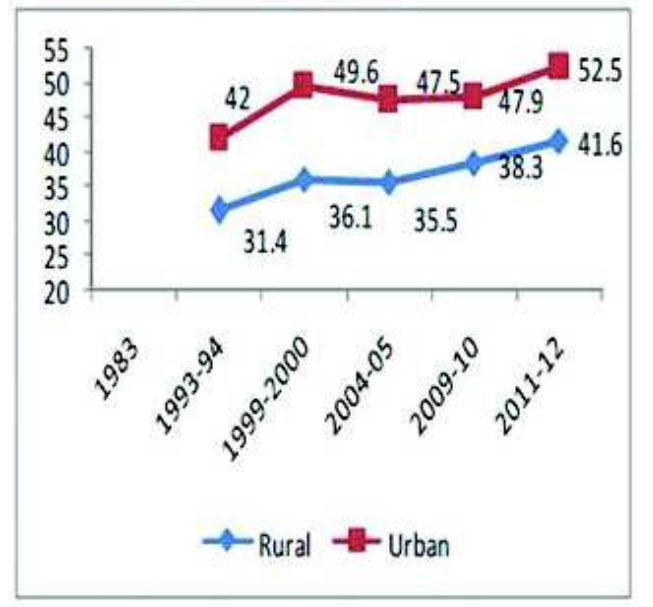

Carbohydrate Intake (per capita g/day)

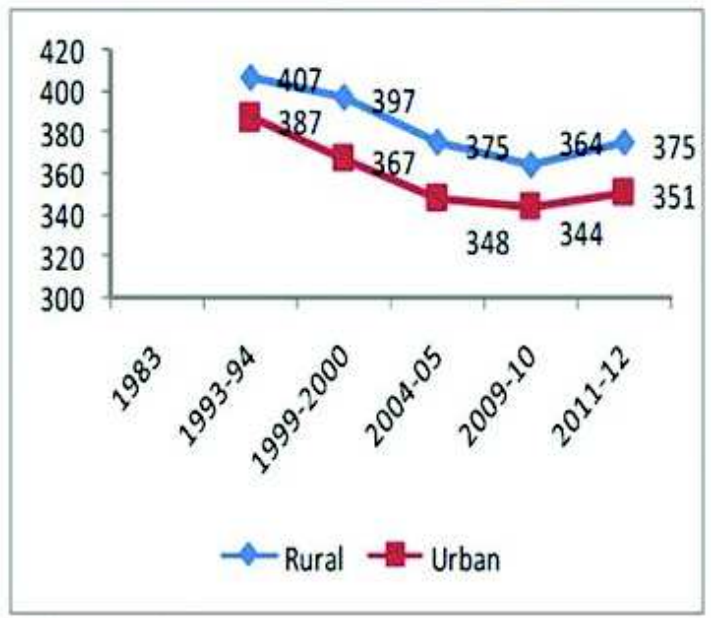

Source: NSSO $68^{\text {th }}$ round, 2014

Figs. 4: Trends in foods and nutrient consumption

Consumption of animal-foods has both beneficial and undesirable health effects. Animal foods help to significantly improve the protein and micronutrient profile in developing world. However excessive meat intake is associated with high saturated fat intake and thereby increases total mortality due to NCDs (Sinha et al., 2009).

\section{Processed Foods}

Most foods are processed to improve the shelf life, taste and reduce wastage and contain huge amounts of sugar, salt and preservatives. In India, though the food processing is in its infancy, it is ranked fifth in terms of production, export and expected growth (Ministry of Food Processing Industries, 2007). Only $25 \%$ is in the organized sector, while $42 \%$ is in unorganized sectors and the rest is from small establishments. It adds to the economy with compound annual growth rate (CAGR) of $8.4 \%$ (Rais et al., 2013).

The marketing of food has clearly influenced dietary shifts. Studies have shown that transnational supermarkets have reduced demand for homemade foods or foods from local markets by expanding available choices of packaged and processed foods to the consumers (Hawkes, 2006). Food sector advertisements targeted at children in Asia, ranges from $25 \%$ in South Korea, to $40-50 \%$ in India, 50$75 \%$ in Pakistan and Philippines, and 70\% in Malaysia (Escalante De Cruz et al., 2004).

\section{Diet and Diabetes}

Diabetes as on 2015 affected $>415$ million adults 
worldwide and is expected to affect 642 million by 2040. India is one of the epicentres of diabetes with 69.2 million adults in 2015, which is projected to increase to 123.5 million in 2040 (IDF, 2015). Anjana et al., 2011 reported that the prevalence of prediabetes and diabetes in India is 77.2 million and 62.4 million respectively. Diabetes is more often encountered in affluent society but very soon it would affect the poorer segments as well and therefore we need to promote simple strategies such as PA and healthier dietary options (Unnikrishnan et al., 2016).

There is a strong association of excessive weight gain particularly central adiposity and risk of developing type 2 diabetes (ADA, 2015). Indians in general have high body fat (visceral fat) for the same BMI. Weight loss diets including exercise (2 to 3 years) improves insulin sensitivity and reduces risk progression from impaired glucose tolerance to type 2 diabetes (Hinderliter et al., 2011). A multi centred long term trial had shown that weight loss of $4-8 \mathrm{~kg}$ in a year in adults with type 2 diabetes resulted in significant improved lipid profile, urinary creatinine and blood pressure (Espeland, 2007). The Indian Diabetes Prevention Programme (IDPP) had shown that physical activity and diet modification (life style modification-LSM) could prevent diabetes in Asian Indians (Ramachandran et al., 2006).

Dietary carbohydrates (dietary glycaemic loadGL) are positively associated with the risk of type 2 diabetes in Indian population. Dietary fibre showed strong inverse association with the risk of type 2 diabetes (Mohan et al., 2009). The high GI and GL diet along with low fibre content increases insulin demand and further leads to pancreatic $\beta$ cell exhaustion, higher lipids with low HDL and waist circumference (Radhika et al., 2009) and CVD (Willett et al., 2002). A recent meta-analysis of cohort studies showed an inverse association between whole grain intake and the risk of type 2 diabetes (Aune $e t$ al., 2013). Substituting brown rice over white rice significantly lowered blood glucose and insulin levels (Sun et al., 2010; Mohan et al., 2014). Higher intake of SSB (1-2 servings a day) showed $26 \%$ greater risk of developing type 2 diabetes independent of obesity leading to inflammation, insulin resistance, and impaired $\beta$-cell function (Malik et al., 2010).

The quality of fat consumed is more important than the total fat intake to support metabolic goals in type 2 diabetes (ADA, 2015). Poor insulin sensitivity is observed with high concentration of SFA in serum lipids and muscle phospholipids (Folosom et al., 1996). In humans, replacement of unsaturated over saturated fats improves insulin sensitivity and metabolic abnormalities (Riccardi et al., 2004). However, a very high intake of omega- 6 PUFA (9-21\%E) with low omega-3 $(0.7 \% \mathrm{E})$ in the diet was positively associated with insulin resistance and metabolic syndrome among Indians (Lakshmipriya et al., 2013). Diets rich in Mono unsaturated fatty acids (MUFA) and omega-3 fatty acids such as Mediterranean dietary pattern as against pharmaceutical preparations of omega3 (Wheeler et al., 2012) have shown beneficial effects on glucose and lipid levels in type 2 diabetes (ADA, 2015).

Proteins (legumes) improve insulin response without altering blood glucose levels and is strongly recommended for reducing the risk of type 2 diabetes (Jenkins et al., 2012). Brown rice with legumes showed 23\% lower glycaemic response compared to white rice diet among overweight Asian Indians (Mohan et al., 2014). Functional foods/ingredients help in reducing blood glucose, lipid levels and inflammation. The details of functional foods are being covered in a separate chapter.

It is common in epidemiology to quantitate risk as convincing, probable, possible and insufficient based on specific criteria and usually prospective cohort studies using disease end points are considered best. The strength of evidences of various dietary factors on risk of type 2 diabetes is shown in Table 1.

\section{Diet and CVD}

CVDs are the leading cause of death worldwide and accounts for $1 / 4^{\text {th }}$ of all deaths in India (Chauhan and Aeri, 2013). Between the year 2003 and 2008 the prevalence of CVDs increased in rural areas (3-6\%) and in the urban areas (8-12\%). Just as for diabetes CVD is high in young adults (Shokeen and Aeri, 2015).

The strength of evidences of various individual nutrients on risk of CVD is shown in Table 2. Though fats have been the focus of attention for CVD, recent analysis of the Minnesota coronary experiment replacing saturated fats with omega 6 indicated that despite the reduction in serum cholesterol it did not reduce mortality from coronary heart disease 
Table 1: Dietary Factors - Strength of Evidences on Type 2 Diabetes Risk

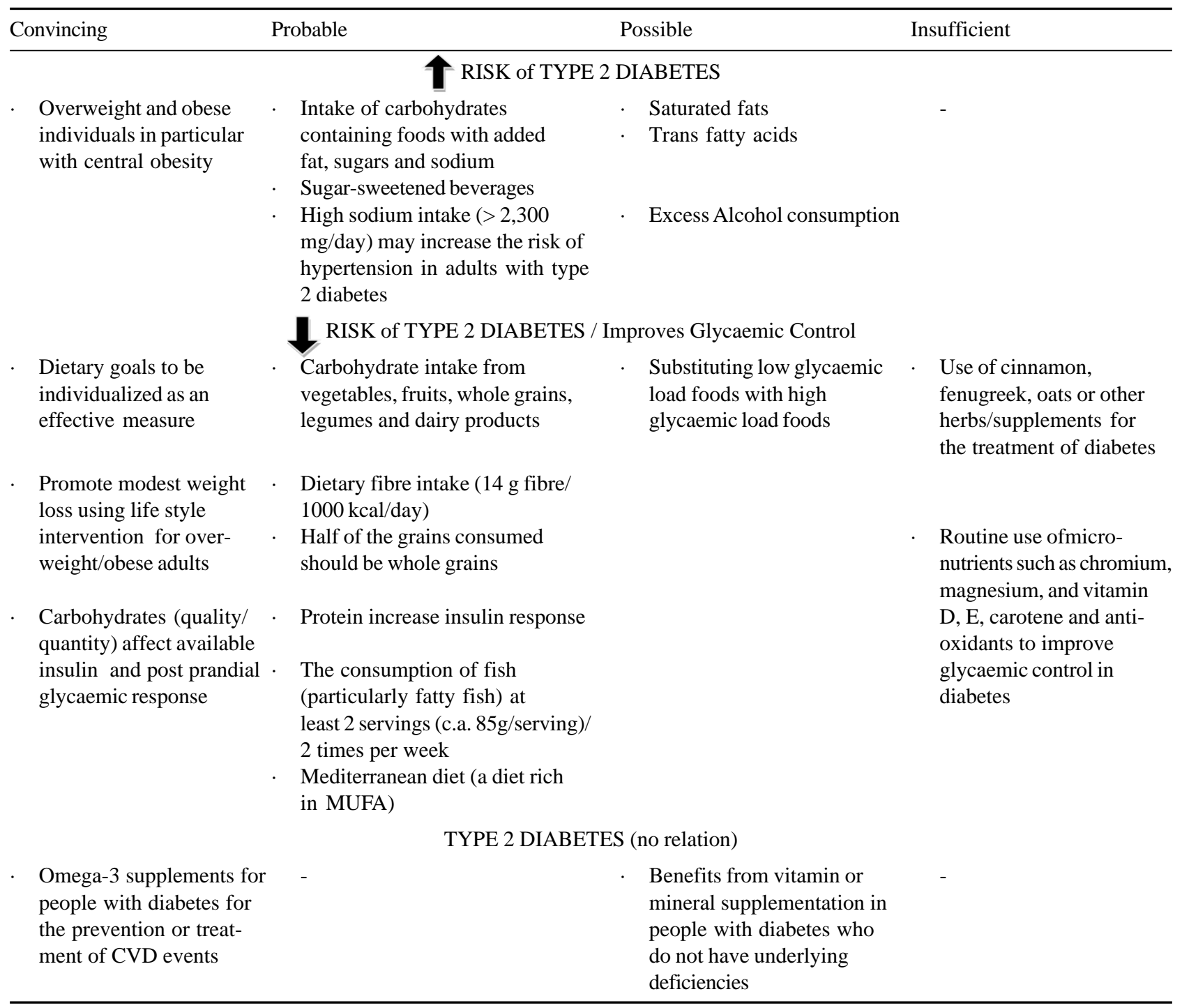

Adapted from ADA 2015

(Veerman, 2016). Cholesterol controversy apparently continues as the recent American dietary guidelines removed limits for dietary cholesterol (USDHHS, 2015-2020).

Compared to individual foods, dietary patterns have more influence on CVD. An INTERHEART study in 52 countries showed unhealthy dietary pattern (western diet) increases the risk of acute myocardial infarction (MI-35\%) globally (Iqbal et al., 2008). Fruits and vegetables consumption accounted for $30 \%$ of risk reduction of MI (Yusuf et al., 2004). Rastogi et al. (2004) showed that consumption of green leafy vegetables associated with a lower risk for ischemic heart disease among Indians. A cross-sectional study among Chennai urban adults showed that high intake of fruit and vegetable resulted in a $48 \%$ protective effect against CVD (Radhika et al., 2008). Investigations suggest that a diversified dietary pattern with healthy nutrients has an aggregated effect on CVD (AHA, 2006).

The three types of diets mainly Dietary Approaches to stop Hypertension (DASH) diet; Mediterranean diet and vegetarian diets have shown better results on decreasing blood lipid and CVD risks. The DASH dietary pattern is high in vegetables, fruits, low-fat dairy products, whole grains, poultry, fish, and nuts and low in sweets, SSBs, red meats, saturated fat, total fat, and cholesterol. It is rich in potassium, 
Table 2: Dietary factors - strength of evidences on CVD risks

\begin{tabular}{ll}
\hline & \\
$\S$ & SFA: Myristic and palmitic acid \\
$\S$ & Trans fatty acids \\
$\S$ & Sodium Intake \\
$\S$ & High alcohol consumption \\
$\S$ & Replacing SFA with TFA
\end{tabular}

$\S \quad$ Dietary cholesterol*

$\S \quad$ Unfiltered boiled coffee

Probable Evidence

\section{Convincing Evidence}

$\S \quad$ Regular physical activity

$\S \quad$ Fish and fish oils (EPA \&DHA)

$\S \quad$ High vegetables and fruits intake

$\S \quad$ Potassium

$\S \quad$ Low to moderate alcohol intake

$\S \quad$ Replacing SFA with carbohydrates

$\S \quad$ Replacing carbohydrates with MUFA

$\begin{array}{ll}\S & \alpha \text { Linolenic acid } \\ \S & \text { Oleic acid } \\ \S & \text { Non starch polysaccharides } \\ \S & \text { Whole grain cereals } \\ \S & \text { Nuts (unsalted) } \\ \S & \text { Plant sterols/stanols } \\ \S & \text { Folate }\end{array}$

Possible Evidence

$\begin{array}{llll}\S & \text { Fats rich in lauric acid } & \S & \text { Flavonoids } \\ \S & \text { Beta carotene supplements } & \S & \text { Soy products }\end{array}$

*Current American dietary guidelines do not emphasize dietary cholesterol as a risk factor.

Adapted from WHO/FAO report 2003 and FAO 2010

magnesium, and calcium, as well as proteins and fibre. Intervention trials of DASH diets have shown promising evidences on low density lipoprotein-LDL and total cholesterol-TC/High density lipoprotein (HDL) ratio and no effect on triglycerides-TG (NHLBI, 2013; Eckel et al., 2014).

Mediterranean diet emphasizes high intake of fresh vegetables, fruits, whole grains, legumes, nuts, and olive oil, moderate to high intake of fish and moderate intake of low fat dairy products, eggs, chicken and small to moderate quantities of wine with meals while red meats are avoided (Shai et al., 2008). The Mediterranean diet tends to be relatively high in dietary fat (40\%-50\% fat calories), predominantly as MUFA $15-25 \%$ while SFA is limited to $\leq 8 \%$ Energy. The Lyon Diet Heart study found that among adults following Mediterranean diet, recurrent CVD was reduced by $70 \%$ (Michel De Lorgeril et al., 1999). An intervention of Mediterranean diet with extravirgin olive oil, or mixed nuts and a control diet (among participants at high CVD risk) demonstrated extravirgin olive oil had $30 \%$ or nuts $28 \%$ reduction in the incidence of major cardiovascular events compared to control diet (Estruch et al., 2006).

The Indian Migration Study (IMS) carried out in 4 cities of India to assess the impact of vegetarian diet (with no animal foods and eggs) showed lower levels of TC, TG, blood pressure and fasting glucose levels compared to non-vegetarians (Shridhar et al., 2014).

\section{Hypertension}

Raised blood pressure (BP), accounts for $54 \%$ of strokes and $47 \%$ of coronary heart disease (Lawes et al., 2008).Excess dietary salt intake accounts for 17-30\% risk for hypertension (WHO, 2012). High dietary salt intake has also been associated with stroke, direct vascular damage, obesity, stomach cancer, osteoporosis, kidney stones and also increased thirst (WHO, 2014). According to a nationwide India Diabetes study, $1 / 5^{\text {th }}$ of the Indian population is hypertensive and consumes dietary salt higher than the recommended $-6 \mathrm{~g} /$ person/day (Bhansali et al., 2014). Radhika et al. (2007) observed that salt intake significantly correlates with the prevalence of hypertension in Chennai urban population. NNMB 
report (2012) indicates that $20 \%$ of hypertensives in rural area consume more than $5 \mathrm{~g} /$ person/day. Adults with type 2 diabetes or at least 3 CVD risk factors on Mediterranean diets showed a reduction of BP by 67/2-3 mm Hg (Eckel et al., 2014). DASH diet is used as an effective dietary measure to manage hypertension (Sacks and Campos, 2010).

\section{Diet and Cancer}

Cancer is the second leading cause of death in developed countries. The immigrant population to the west develops cancers similar to that of the country migrated. Cancers in developing countries is also on the rise with an urban rural divide in the prevalence and types of cancer.

Cancers are both due to external and internal insults resulting in cumulative effects leading to DNA damage/mutations which over a period of time progress to overt cancer manifestations. A detailed discussion of the carcinogenic process is beyond the scope of this article.

The total deaths estimated worldwide were 8.2 million and by 2030, the global burden is expected to grow to $21.7 \times 10^{6}$ (new cancer cases with $13 \times 10^{6}$ deaths-American Cancer Society, 2015). Nearly $25 \times 10^{5}$ of cancer cases are diagnosed and $5.5 \times 10^{5}$ deaths occur annually due to cancer in India (Das and Petro, 2010). The three most prevalent fatal cancers are oral [lip and pharynx, (22.9\%)], stomach $(12.6 \%)$ and lung (including trachea and larynx)$11.4 \%$ in men, and cervical (17.1\%), stomach (14.1\%), and breast $(10.2 \%)$ in women. Tobacco related cancers represent $42 \%$ of male and $18.3 \%$ of female cancer deaths (Dikshit et al., 2012).

The World Cancer Research Fund estimates suggest that between one-fifth and one-fourth of cancers worldwide are related to overweight or obesity, physical inactivity, and/or poor nutrition (WCRF/AICR, 2007). India has lower rates of cancer than the western countries but has very few epidemiological studies, which highlight the role of diets in relation to cancer.

A review of a few studies conducted in India, and Indian migrants in Singapore documented reduced risk for oral, oesophageal, breast, endometrial, cervical cancers with high intake of vegetables, fruits, fish, eggs and diets high in carotenoids and nutrients such as Vitamins C and E (Sinha et al., 2003). Similar findings were reported in upper aerodigestive cancer (oropharyngeal, larynx and oesophagus) such as reduced intake of vegetables/fruits, pulses, fish and low intakes of $\beta$ carotene, Vitamins A, B complex, C and selenium. Increased energy intake as a risk factor for breast cancers was also documented (Krishnaswamy and Prasad, 1995). A decreased risk was also noted with higher physical activity for breast cancers and consumption of green tea, turmeric, and basil for stomach cancers. On the other hand betel quid chewing, reverse smoking, consumption of chillies and salted tea enhanced upper aerodigestive cancers (Rajkumar et al., 2003; Nayar et al., 2000). Higher body mass index and intake of saturated fats enhanced risk of ovarian, and breast cancer while dried fish, high temperature foods, chillies and spicy foods increased risk of stomach cancers (Mathew et al., 2000). However all the studies reviewed suffer from inadequate sample size, non-standardized dietary protocols for recall of past intake and imperfect statistical procedures and hence difficult to draw firm conclusions.

Unlike the situation in India, in Western Countries, large prospective cohort studies with more elaborate statistics for arriving at causal effects have been reported. The most authoritative account of cancers at several sites and effects of food, nutrition and PA has been documented (WCRF/AICR, 2007). The evidence based science were gathered from systematic reviews and experts panel opinion. They had identified foods/drinks, obesity/body composition as modifiable exposure factors and global preventive measures applicable to populations and individuals were given (Table 3). A summary of findings, proscriptive and prescriptive approaches for cancer prevention, which can be applied to other chronic diseases as well, are as follows:

1. One should be lean and within the normal range of BMI (18.5-23 for Indians), and should avoid weight gain and increase in waist circumference throughout adulthood. Both over weight and obesity enhance the risk of cancers.

2. PA is as important as diet and Physical activity levels (PAL-total energy expenditure as a multiple of basal metabolic rate) to be maintained $>1.6$. 
Table 3: Anthropometric parameters, foods, beverages and physical activity on cancer risk

\begin{tabular}{|c|c|c|c|}
\hline \multirow[t]{2}{*}{ Parameters } & \multirow[t]{2}{*}{ Cancers } & \multicolumn{2}{|c|}{ Risk } \\
\hline & & Reduced & Enhanced \\
\hline \multicolumn{4}{|c|}{ Convincing evidence } \\
\hline Attained height & Breast-post menopause, Colorectum, Ovary & & $\uparrow$ \\
\hline Abdominal fat & Colorectum & & $\uparrow$ \\
\hline Body fatness & $\begin{array}{l}\text { Oeasophagus, Pancreas, Colorectum, Prostate, Endometrium, } \\
\text { Breast-post menopause, Kidney }\end{array}$ & & $\uparrow$ \\
\hline Physical activity & Colorectum, weight gain, OW, OB & $\downarrow$ & \\
\hline Sedentary living & Weight gain, $\mathrm{OW}, \mathrm{OB}$ & & $\uparrow$ \\
\hline Lactation & Breast-pre \& post Menopause & $\downarrow$ & \\
\hline Red and processed meat & Colorectum & & $\uparrow$ \\
\hline Aflatoxin & Liver & & $\uparrow$ \\
\hline Arsenic in drinking water & Lung & & $\uparrow$ \\
\hline Alcoholic drinks & $\begin{array}{l}\text { Mouth, Pharynx, Larynx, Oeasophagus, Breast-pre \& post } \\
\text { menopause, Colorectum (men), }\end{array}$ & & $\uparrow$ \\
\hline$\beta$ carotene as pharmaceutical supplement & Lung & & $\uparrow$ \\
\hline \multicolumn{4}{|c|}{ Probable evidence } \\
\hline Adult weight gain & Breast- post menopause & & $\uparrow$ \\
\hline Body fatness & Gall bladder, Ovary & & $\uparrow$ \\
\hline Abdominal fatness & Pancreas, Breast-post menopause, Endometrium & & $\uparrow$ \\
\hline Attained height & Pancreas, Breast-pre menopause & & $\uparrow$ \\
\hline Body fatness & Breast-pre menopause & $\downarrow$ & \\
\hline Being breast fed & Low weight gain, low OW/OB & $\downarrow$ & \\
\hline Greater birth weight & Breast-pre menopause & & $\uparrow$ \\
\hline Physical activity & Breast-post menopause, Endometrium & $\downarrow$ & \\
\hline Energy dense foods & Weight gain, OW, OB & & $\uparrow$ \\
\hline Low energy-dense food & Low weight gain, low OW/OB & $\downarrow$ & \\
\hline Diets high in calcium & Colorectum & $\downarrow$ & \\
\hline Cantonese style-salted fish & Nasopharynx & & $\uparrow$ \\
\hline Salt, salty foods & Stomach & & $\uparrow$ \\
\hline Diets high in calcium & Prostate & & $\uparrow$ \\
\hline Foods containing fibre & Colorectum & $\downarrow$ & \\
\hline Non-starchy vegetables & Mouth, Pharynx, Larynx , Oeasophagus, Stomach & $\downarrow$ & \\
\hline Foods containing folate & Pancreas & $\downarrow$ & \\
\hline Foods containing lycopene/Selenium & Prostate & $\downarrow$ & \\
\hline Allium vegetables & Stomach & $\downarrow$ & \\
\hline Fruits & Mouth, Pharynx, Larynx, Oeasophagus, Lung, Stomach & $\downarrow$ & \\
\hline Garlic & Colorectum & $\downarrow$ & \\
\hline Arsenic in drinking water & Skin & & $\uparrow$ \\
\hline Alcoholic drinks & Liver, Colorectum (women) & & $\uparrow$ \\
\hline Mate & Oeasophagus & & $\uparrow$ \\
\hline Sugary drinks & Weight gain, OW,OB & & $\uparrow$ \\
\hline
\end{tabular}

OW - Over Weight; OB - Obesity. Possible and Insufficient evidences are not indicated.

Source: WCIR and AICR, 2007. 
3. Energy -dense foods need to be limited and sugary drinks to be avoided. Calorie content should not exceed $125 \mathrm{kcal}$ per $100 \mathrm{~g}$ of food as they promote obesity. Fast foods should be taken sparingly.

4. Foods of plant origin such as non starchy vegetables and fruits $(400 \mathrm{~g} / \mathrm{d})$ with unprocessed cereal grains (unrefined) and legumes (whole grams) must be consumed every day. They provide fiber, phyto and micro nutrients.

5. Individuals must limit the intake of red meat (not more than 300g/person/week) and avoid processed meat.

6. Must avoid mouldy grains/legumes (contains mycotoxins-aflatoxins and others).

7. Salt intake from all sources (cooking salt, salt preserved home foods and processed foods) should not exceed 5-6g/ day (2-2.5 g of sodium).

8. Exclusive breast feeding should be practiced for the first 6 months as it protects both the mother from cancers and the child from future risks of obesity and NCDs.

9. Alcohol intake to be limited ( $\leq 2$ drinks for men and one for women/day as several cancers and other NCDs are aetiologically related to higher intake.

10. Dietary supplements are not recommended for cancer prevention and nutritional supplements for patients to be taken under medical supervision.

\section{Policies and Programs}

The rising tide of NCDs is a great public health challenge next only to tobacco consumption needing proactive steps within a broad frame work, impacting common risk factors. (Beaglehole et al., 2011). Dietary patterns may hold great promise in averting NCDs (Mozaffarian, 2016).

WHO, 2014 has set targets to be achieved by 2025 such as a $25 \%$ reduction in overall mortality, $10 \%$ reduction in prevalence of physical inactivity as also harmful use of alcohol consumption, a 30\% reduction in prevalence of tobacco use, $30 \%$ reduction in salt/sodium intake, $25 \%$ reduction in high $\mathrm{BP}$ and stop the rising menace of obesity and NCDs starting from childhood/adolescent age. A broad integrated framework should include evidence-based strategies cutting across major risk factors including maternal and child under-nutrition to combat dual burden of diseases in India. Comprehensive and coherent approaches involving several players are needed. A strong political commitment, informed health sector, cooperative private sectors and energetic civil societies need to work in consensus to achieve the targets. A focused attention and an enabling environment are essential for individuals, community and populations at large to adopt best measures.

The various policies and programs need to be integrated with advocacy for enhancing awareness among all stakeholders (Krishnaswamy and Laxmaiah, 2011). The government has to be committed and provide resources and merge it with existing infrastructure for sustainability. The following need emphasis to address life styles practices:

1. Food, Nutrition and Agricultural policies to enhance availability, accessibility and affordability of foods to promote Health/ Nutrition.

2. Health policy and programs must concentrate on early detection and treatment and catalyse behavioural changes to promote quality diet and patterns conducive for good physiological and metabolic health. Health system needs a restructuring including primary health care.

3. Pricing, public distribution, excise taxes and incentives are required to enable community to prefer healthy choices.

4. Food laws and legislations to promote healthy diet and ban aggressive promotional strategies and improper/dubious advertisements particularly for children and adolescents.

5. Urban/rural planning with appropriate facilities such as community parks, walking and cycling pathways are essential

6. School health programs have to concentrate on children and adolescents to curtail obesogenic environment and promote physical fitness. 
7. Improving canteens in industries and other food service establishments is an important activity.

8. Promote public private partnerships to make available healthy alternative choices of processed foods with mandatory labelling.

9. It is necessary to upgrade nutrition education/ knowledge and build skills in paramedical personnel, empower women, adolescents and children as change agents to facilitate compliance in the community. Social marketing strategies and mass media interventions can play a major role to influence behavioural changes.

10. Dietary and physical activity guidelines need to be formulated and widely circulated.

11. Establish a national multi-sectoral body for planning, guiding, implementing and monitoring activities for prevention and control of NCDs and build capacity at all levels.

Needleless to reiterate that political commitment, leadership at several levels and focused approaches are the back bone of any preventive strategy. The Government of India after consultation process with stake holders has launched a program for prevention and control of cancer, diabetes, CVD, COPD and stroke in 2010. The program is under implementation in 100 districts and is a multi-sectoral plan to cover all districts in a phased manner. The framework has 21 indicators and 10 targets in line with WHO targets with additional inputs to control indoor pollution due to cooking fuel. They are indicated in Fig. 5 (MOHFW, 2013).

\section{Conclusions}

Globally NCDs are major causes for morbidity and mortality. NCDS are more challenging in developing countries affecting young people with premature deaths creating innumerable hardships for the family. The NCDs are escalating primarily due to demographic, socioeconomic variations and technological innovations in diverse arena compounded by urbanization, globalization/trade liberalization with strong market forces (mega market chains) promoting consumerism and food culture change.

India is passing through the same wave of drivers (risk factors) for dual burden of diseases imposing a heavy economic burden on the family and health

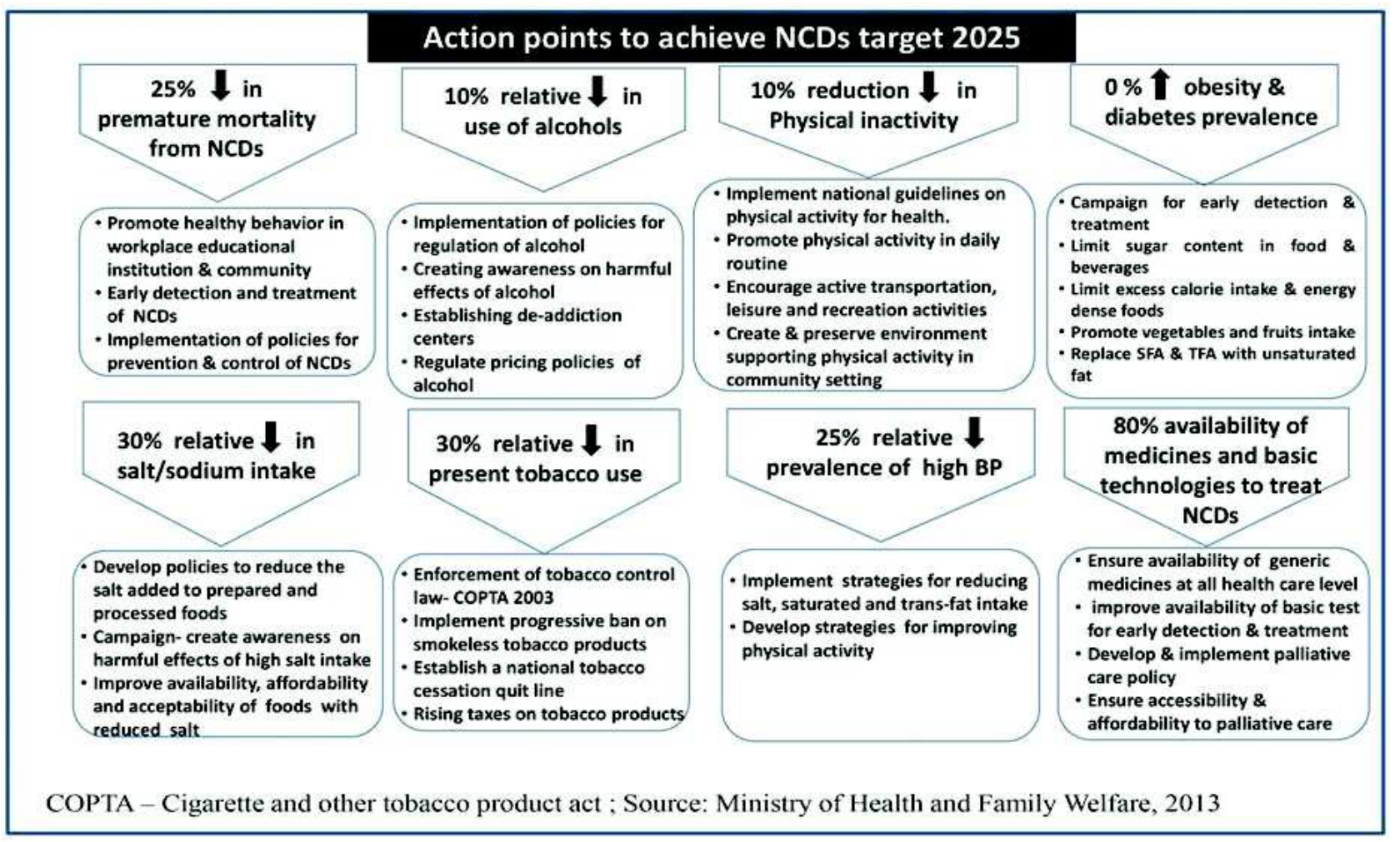

Fig. 5: Action points to achieve NCDs target 2025 
systems. A transition from traditional foods which are minimally processed to refined foods with enhanced intake of sugars, oils, hydrogenated fat ('vanaspati') containing trans-fat, saturated fat, SSBs, animal foods, dairy foods and salty snacks with little awareness has shifted the entire food environment pattern. Moreover whole grains, nuts, pulses and legumes; and vegetables and fruits, which favourably impact disease processes, are not consumed in required quantities. On the other hand processed and convenience snacks, street foods and ready-to-eat meals are on an increase due to taste preferences, availability in supermarkets/fast-food outlets and women choosing to prefer economically remunerative jobs in urban areas slowly eroding traditional household cooking.

CVD, diabetes and cancer are escalating in India and it is essential to accelerate preventive strategies. A massive nutrition education program using diverse strategies and a life course perspective of preventive

\section{References}

Abegunde D, Stanciole A (2006) An estimation of the economic impact of chronic non-communicable diseases in selected countries. WHO Working Paper. Geneva. Source: http:// www.who.int/chp/working_paper_growth\% 20model29may.pdf assessed on 12th Feb 2016

American Cancer Society (2015) Global Cancer Facts \& Figures 3rd Edition, Atlanta

American Diabetes Association (2015) Standards of medical care in diabetes-2015 abridged for primary care providers. Clinical Diabetes 33 97-111

Anand S S, Hawkes C, De Souza R J et al. (2015) Food consumption and its impact on cardiovascular disease: Importance of solutions focused on the globalized food system: A report from the Workshop Convened by the World Heart Federation J Am Coll Cardiol 66 1590-1614

Anjana R M Pradeepa R, Deepa M et al. (2011) ICMR-INDIAB Collaborative Study Group: Prevalence of diabetes and prediabetes (impaired fasting glucose and/or impaired glucose tolerance) in urban and rural India: phase I results of the Indian Council of Medical Research-INdiaDIABetes (ICMR-INDIAB) study Diabetologia 54 3022-7

Aune D, Norat T, Romundstad P et al. (2013) Whole grain and refined grain consumption and the risk of type 2 diabetes: a systematic review and dose-response meta-analysis of cohort studies Eur J Epidemiol 28 845-858 steps with emphasis on removing barriers to healthy eating and physical inactivity are essential.

Comprehensive policies and programs on evidence-based sciences that are cost effective and sustainable to address under and over nutrition are essential. Regulatory bodies need to be vigilant exercising their authority to keep unhealthy substances within limits. Public private partnerships must have common goals to promote healthy choices.

The Government of India has embarked on NCD prevention strategy with several actions oriented programs. The program has both primary and secondary prevention covering several risky behaviours. With a strong political commitment and leadership within the Health Ministry, India hopes to win the war against the NCDs, which is multi -factorial in origin and multifaceted in presentation and requires multipronged approach for prevention and control.

Barker D J (1998) In utero programming of chronic disease Clinical science 95 115-28

Basu S, McKee M, Galea G et al. (2013) Relationship of soft drink consumption to global overweight, obesity, and diabetes: A cross-national analysis of 75 countries Am J Pub Health 103 2071-7

Beaglehole R, Bonita R, Horton R et al. (2011) Priority actions for the non-communicable disease crisis Lancet 377 14381447

Bhansali A, Dhandania V K, Deepa M et al. (2014) Prevalence of and risk factors for hypertension in urban and rural India: the ICMR-INDIAB study J Human Hypertension $29204-$ 209

Bloom D E, Cafiero E T, Jané-Llopis E et al. (2011) The World Economic Forum and Harvard School of Public Health. The global economic burden of non-communicable diseases [online] Source:_http://www3.weforum.org/docs/WEF_ Harvard_HE_Global Economic Burden Non Communicable Diseases_2011.pdf assessed on 6th Jan 2016.

Census of India. SRS statistical report (2013) Source: www.censusindia.gov.in/vital_statistics/SRS_Reports_ 2013. htmlassessed on 15th Jan 2016

Chauhan S, Aeri BT (2013) Prevalence of cardiovascular disease in India and it is economic impact-A review Int J Scientific Research Publications 3 1-5 
Credit Suisse (2015) Global Wealth Report 2015 October, Switzerland: Credit Suisse, Research Institute. Source: https://publications.credit-suisse.com/tasks/render/file/ ?fileID =F2425415-DCA7-80B8- EAD989AF9341D47E accessed on 7 December 2015.

Das S and Patro K C (2010) Cancer care in the rural areas of India: A firsthand experience of a clinical oncologist and review of literatures J Cancer Research Therapeutics 6 299-303

Delgado C L (2003) Rising consumption of meat and milk in developing countries has created a new food revolution $J$ Nutr 133 3907S-3910S

Dikshit R, Gupta P C, Ramasundarahettige C et al. (2012) Million Death Study Collaborators Cancer mortality in India: a nationally representative survey Lancet 379 1807-16

Eckel R H, Jakicic J M, Ard J D et al. (2014) 2013 AHA/ACC guideline on lifestyle management to reduce cardiovascular risk: a report of the American College of Cardiology/ American Heart Association Task Force on Practice Guidelines J Amr Col Cardiol 63 (25-PA)

Engelgau M M, El-Saharty S, Kudesia P et al. (2011) Capitalizing on the demographic transition: tackling non communicable diseases in South Asia. World Bank Publications. Source:http://siteresources.worldbank.org/SOUTH ASIAEXT/Resources/223546-1296680097256/77074371296680114157/NCDs_South_Asia_February_2011.pdf assessed on 24th Feb 2016

Escalante de Cruz A, Phillips S, Visch M et al. (2004) The junk food generation: A multi-country survey of the influence of television advertisements on children. Kuala Lumpur, Malaysia: Consumers Interna-tional, Asia Pacific Office

Espeland M (2007) Reduction in weight and cardiovascular disease risk factors in individuals with type 2 diabetes: one-year results of the look AHEAD trial Diabetes care 1-23

Estruch R, Martinez-Gonzalez M A, Corella D et al. (2006) Effects of a Mediterranean-style diet on cardiovascular risk factors: a randomized trial Annals Internal Med 145 111

FAO (2004) The State of Agricultural Commodity Markets. Source: www.fao.org/3/a-y5419e.pdf assessed on 12th Jan 2016

FAO (2010) Fats and fatty acids in human nutrition Report of an expert consultation. Source: http://www.fao.org/3/ai1953e.pdf assessed on 16th Jan 2016

Folsom A R, Ma J, McGovern P G et al. (1996) Relation between plasma phospholipid saturated fatty acids and hyperinsulinemia Metabolism 45 223-228

Foodnavigator-USA.com, 2011 PepsiCo and Coca-Cola's profit aided by growth in emerging markets [online document].
Source: http://www.foodnavigatorusa.com/content/ view/ print/388021 assessed on 13/12/2015)

FSSAI (2010) Regulation of trans fatty acids (TFA) in partially hydrogenated vegetable oil (PHVO's). Source: http:// www.fssai.gov.in/Portals/0/Regulation_of_TFA_.pdf assessed on16th March 2015

Ghafoorunissa G (2007) Role of trans fatty acids in health and challenges to their reduction in Indian foods Asia Pacific J Clin Nutr 17 212-215

Gulati S, Misra A (2014) Sugar Intake, Obesity, and Diabetes in India. Nutrients 6 5955-5974

Hallal PC, Andersen LB, Bull FC (2012) Lancet Physical Activity Series Working Group. Global physical activity levels: surveillance progress, pitfalls, and prospects. Lancet 380 247-257

Hawkes C (2006) Uneven dietary development: linking the policies and processes of globalization with the nutrition transition, obesity and diet-related chronic diseases Globalization and health $\mathbf{2 8 2} 1$

Hinderliter A L, Babyak M A, Sherwood A et al. (2011) The DASH diet and insulin sensitivity Current hypertension reports 13 67-73

The Hindu (2006) The food habits of a nation. Source: http:// www.thehindu.com/todays-paper/the-food-habits-of-anation/article3089973.ece assessed on 15th March 2016

Hu F B (2003) Plant-based foods and prevention of cardiovascular disease: an overview Am J Clin Nutr 78 544S-551S

Hu F B (2011) Globalization of diabetes: the role of diet, lifestyle, and genes Diab Care 34 1249-57

IDF (2015) International Diabetes Federation IDF Diabetes, 7 ed. Brussels, Belgium: International Diabetes Federation, 2015. Source: http://www.diabetesatlas.org

International trade statistics (2015) World trade organization. Source: https://www.wto.org/english/res_e/statis_e/ its2015_e/its2015_e.pdf accessed on 24th Feb 2016

Iqbal R, Anand S, Ounpuu S et al. (2008) Dietary patterns and the risk of acute myocardial infarction in 52 countries: results of the INTERHEART study Circulation 118 19293

Jenkins D J, Kendall C W, Augustin L S et al. (2012) Effect of legumes as part of a low glycemic index diet on glycemic control and cardiovascular risk factors in type 2 diabetes mellitus: a randomized controlled trial Archives of Internal Med 172 1653-1660

Kapil U and Sachdev H P S (2012) Urgent need to orient public health response to rapid nutrition transition Ind $J$ Community Med $\mathbf{3 7} 207$ 
Kearney J (2010) Food consumption trends and drivers Philosophical Transactions of the Royal Society of London B: Biological Sciences 365 2793-2807

Krishnaswamy K and Laxmaiah A (2011) Nutrition related noncommunicable disorders. In: Public health nutrition in developing countries (Edited by Vir S H) pp 956981, Woodhead publishing India Pvt. Ltd., Cambridge \& New Delhi, 2011

Krishnaswamy K and Prasad M R P (1995) Profile of cancers in India: Possible role of dietary factors. pp 61-70, In Diet, Nutrition and chronic disease- An Asian perspective. (eds) Shetty and P and Gopalan C. Smith-GordanNishimura, UK 1995

L'Abbé M R, Stender S, Skeaff C M et al. (2009) Approaches to removing trans fats from the food supply in industrialized and developing countries Eur J Clin Nutr 63 S50-S67

Lakshmipriya N, Gayathri R, Praseena K et al. (2013) Type of vegetable oils used in cooking and risk of metabolic syndrome among Asian Indians Int J Food Sci Nutr 64 131-139

Lawes C M, Vander Hoorn S and Rodgers A (2008) International Society of Hypertension. Global burden of blood pressure related disease, 2001 Lancet 371 1513-38

Lustig R H, Schmidt L A and Brindis C D (2012) Public health: The toxic truth about sugar. Nature 482 27-29

Malik V S, Popkin B M, Bray G A et al. (2010) Sugar-sweetened beverages and risk of metabolic syndrome and type 2 diabetes a meta-analysis Diabetes care 33 2477-2483

Marshall S J (2004) Developing countries face double burden of disease Bulletin of the World Health Organization 82556

Mathew A, Gangadharan P, Varghese C et al. (2009) Diet and stomach cancer: A case-control study in South India Eur J Cancer Prev 9 89-97

Michel de Lorgeril M, Salen P, Martin J L et al. (1999) Mediterranean diet, traditional risk factors, and the rate of cardiovascular complications after myocardial infarction Heart failure $\mathbf{1 1} 6$

Ministry of Food Processing Industries (MOFPI) (2008-09), Government of India, Annual Report. New Delhi, India. Source: http://mofpi.nic.in/H_Dwld.aspx?KYEwmOL +HGpoo8D1NKVV3fE4aW5+awTGdnZC9kP6Bh/ lo1hB7dyEw==assessed o $14^{\text {th }}$ March 2016

Ministry of health and family welfare (MOHFW) (2013) National programme for prevention and control of cancer, diabetes, cardiovascular disease and stroke. Source: http:// mohfw.nic.in/index 1 .php?lang=1\&level=3\& sublinkid= $3627 \&$ lid=2194 assessed on 18th March 2016
Misra A, Khurana L, Isharwal S et al. (2009) South Asian diets and insulin resistance Br J Nutr 101 465-73

Mohan V, Radhika G, Sathya R M et al. (2009) Dietary carbohydrates, glycaemic load, food groups and newly detected type 2 diabetes among urban Asian Indian population in Chennai, India (CURES 59) Br J Nutr 102 1498-1506

Mohan V, Spiegelman D, Sudha V et al. (2014) Effect of brown rice, white rice, and brown rice with legumes on blood glucose and insulin responses in overweight Asian Indians: A randomized controlled trial Diab Technol Therapeutics 16 317-325

Mozaffarian D (2016) Dietary and Policy Priorities for Cardiovascular Disease, Diabetes, and Obesity A Comprehensive Review Circulation 133 187-225

MWCD (2015) Report of Working Group on Addressing Consumption of Foods High in Fat, Salt and Sugar (HFSS) and Promotion of Healthy Snacks in Schools of India. 2015. Prepared by Working Group Constituted by Ministry of Women and Child Development Government of India

National Council of applied economic research (2014) An analysis of changing food consumption pattern in India

National Heart, Lung, and Blood Institute (NHLBI) (2013) Your guide to lowering your blood pressure with DASH

National Sample Survey Organisation (2010): Migration in India, Report No. 533, Ministry of Statistics and Programme Implementation, Government of India, New Delhi

Nayar D, Kapil U, Joshi Y K et al. (2000) Nutritional risk factors in esophageal cancer J Assoc Physicians India 48 781-7

NNMB (2012) National Nutrition Monitoring Bureau. NNMB Technical report no. 26. Source:_http://nnmbindia.org/ 1_NNMB_Third_Repeat_Rural_Survey___Technicl_ Report_26.pdf assessed on March 19 2016

NSSO (2014) NSS $68^{\text {th }}$ round National Sample Survey Office. Report. Government of India

Patel V, Chatterji S, Chisholm D et al. (2011) Chronic diseases and injuries in India Lancet 377 413-28

Popkin B M, Adair L S and Ng S W (2012) Global nutrition transition and the pandemic of obesity in developing countries Nutr Rev 70 3-21

Popkin B M, Ng S W, Mhurchu C N et al. (2010) Beverage Patterns and Trends in the United Kingdom. Chapel Hill, NC: University of North Carolina, 2010

Radhika G, Sathya R M, Ganesan A et al. (2011) Dietary profile of urban adult population in South India in the context of chronic disease epidemiology (CURES-68) Pub Health 
Nutr 14 591-598

Radhika G, Sathya R M, Sudha V et al. (2007) Dietary salt intake and hypertension in an urban south Indian population [CURES 53] J Assoc Physicians of India 55 405-11

Radhika G, Van Dam R M, Sudha V et al. (2009) Refined grain consumption and the metabolic syndrome in urban Asian Indians (CURES 57) Metabolism 58 675-681

Rais M, Acharya S and Sharma N (2013) Food Processing Industry in India: S\&T Capability, Skills and Employment Opportunities J Food Process Technol 4 doi: 10.4172/ 2157-7110.1000260

Rajkumar T, Sridhar H, Balaram P et al. (2003) Oral cancer in Southern India: the influence of body size, diet, infections and sexual practices Eur J Cancer Prev 12 135-43

Rastogi T, Reddy K S, Vaz M et al. (2004) Diet and risk of ischemic heart disease in India The Am J Clin Nutr 79582592

Radhika G, Sudha V, Sathya R M et al. (2008) Association of fruit and vegetable intake with cardiovascular risk factors in urban south Indians Br J Nutr 99 398-405

Ramachandran A, Snehalatha C, Mary S, Mukesh B, Bhaskar A D and Vijay V (2006) The Indian Diabetes Prevention Programme shows that lifestyle modification and metformin prevent type 2 diabetes in Asian Indian subjects with impaired glucose tolerance (IDPP-1) Diabetologia 49 289-297

Ramachandran P (2011) Nutrition transition in India Bulletin of the Nutrition Foundation of India $\mathbf{3 2}$

Reddy K S (2002) Cardiovascular diseases in the developing countries: dimensions, determinants, dynamics and directions for public health action Public Health Nutr $\mathbf{5}$ 231-7

Riccardi G, Giacco R and Rivellese AA (2004) Dietary fat, insulin sensitivity and the metabolic syndrome Clin Nutr 23447 456

Sacks F M and Campos H (2010) Dietary therapy in hypertension $N$ Engl J Med 362 2102-2112 doi: 10.1056/NEJMct 0911013

Shai I, Schwarzfuchs D, Henkin Y et al. (2008) Weight loss with a low-carbohydrate, Mediterranean, or low-fat diet New Eng J Med 359 229-241

Shetty P (2003) Impact of globalisation on food and agriculture from the farm to the plate. In Workshop on Impacts of Globalization on Agricultural Production and Marketing with Focus on Food Quality, Tokyo (Japan), 22-24 Jan 2003, Japan FAO Association

Shobana S, Malleshi N G, Sudha V et al. (2011) Nutritional and sensory profile of two Indian rice varieties with different degrees of polishing Int J Food Sci Nutr 62 800-810

Shokeen D and Aeri B T (2015) Risk Factors Associated with the Increasing Cardiovascular Diseases Prevalence in India: A Review J Nutr Food Sci 5 doi: 10.4172/2155-9600.1000331

Shridhar K, Dhillon P K, Bowen L et al. (2014) The Association between a Vegetarian Diet and Cardiovascular Disease (CVD) Risk Factors in India: The Indian Migration Study PloS one 9(10) e110586

Sinha R, Anderson D E, McDonald S S et al. (2003) Cancer risk and diet in India $J$ Postgrad Med 49 222-228

Sinha R, Cross A J, Graubard B I et al. (2009) Meat Intake and Mortality: A Prospective Study of Over Half a Million People Arch Intern Med 169 562-571

Stuckler D, McKee M, Ebrahim S, et al. (2012) Manufacturing epidemics: The role of global producers in increased consumption of unhealthy commodities including processed foods, alcohol, and tobacco PLoS Med 9(6) e1001235

Subramanian S V, Corsi D J, Subramanyam M A et al. (2013) Jumping the gun: the problematic discourse on socioeconomic status and cardiovascular health in India Int J Epidemiol 42 1410-26

Sun Q, Spiegelman D, van Dam R M et al. (2010) White rice, brown rice, and risk of type 2 diabetes in US men and women Archives Internal Med 170 961-969

Swaminathan S and Vaz M (2013) Childhood Physical Activity, Sports and Exercise and Noncommunicable Disease: A Special Focus on India Indian J Pediatr 80 (Suppl 1) S63S70 DOI 10.1007/s12098-012-0846-1

Taylor F C, Satija A, Khurana S et al. (2011) Pepsi and Coca Cola in Delhi, India: availability, price and sales Public Health Nutr 14 653-60

Thakur J S, Prinja S, Garg C C et al. (2011) Social and economic implications of noncommunicable diseases in India Ind $J$ Community Medicine 36 13-15

Unnikrishnan R, Anjana R M and Mohan V (2016) Diabetes mellitus and its complications in India Nature Reviews Endocrinology Doi:10.1038/nrendo.2016.53

US Department of Health and Human Services. Dietary guidelines for Americans, 2015-2020, Eigth Edition, health.gov/ dietaryguidelines/2015/guidelines/ accessed on 24th April 2016

Veerman J L (2016) Dietary fats: a new look at old data challenges established wisdom. BMJ, 353, 1512. doi:10.1136/ bmj.i1512

Warburton D E R, Nicol C W and Bredin S S D (2006) Health 
benefits of physical activity: the evidence CMAJ 174801 809

Wheeler M L, Dunbar S A, Jaacks L M et al. (2012) Macronutrients, food groups, and eating patterns in the management of diabetes: a systematic review of the literature, 2010. Diabetes Care 35 434-445

WHO (2010) Global recommendations on physical activity for health. Source: http://www.who.int/dietphysicalactivity/ publications/9789241599979/en

WHO (2007) Commission on Social Determinants of Health Globalization. Food and Nutrition Transitions Source: www.who.int/social_determinants/resources/gkn_hawkes. pdf accessed on 25th Feb 2016)

WHO (2010) Global status report on non-communicable diseases. (Source: www.who.int/nmh/publications/ncd_report_full_ en.pdfassessed on 6th Jan 2016)

WHO (2013) Global action plan for the prevention and control of noncommunicable diseases 2013-2020. Source

WHO (2014) Global status report on noncommunicable diseases Source: www.who.int/nmh/publications/ncd-status-report2014/en/assessed on 6th Jan 2016)

WHO (2014a) Non communicable diseases-Country profile, (Source: www.who.int/nmh/publications/ncd-profiles2014/en/assessed on 8th Jan 2016)

WHO/FAO (2003) Joint WHOD FAO Expert Consultation on Diet, Nutrition and the Prevention of Chronic Diseases.
Diet, nutrition and the prevention of chronic diseases: Report of a joint WHOD FAO expert consultation, Geneva, 28 January - 1 February 2002. WHO Technical Report Series 916, Geneva

Willett W, Manson J and Liu S (2002) Glycemic index, glycemic load, and risk of type 2 diabetes Amr J Clin Nutr 76 274S$280 \mathrm{~S}$

World Bank Report (2014) Source: http://data.worldbank.org/ indicator/SP.URB.TOTL. IN.ZS assessed on 14th March 2016

World Cancer Research Fund/American Institute for Cancer Research (2007) Food, nutrition, physical activity, and the prevention of cancer: a global perspective. American Institute for Cancer Research Washington, DC

Xavier D, Pais P, Devereaux P J et al. (2008) Treatment and outcomes of acute coronary syndromes in India (CREATE): A prospective analysis of registry data Lancet 371 1435-42

Yajnik C S (2004) Early life origins of insulin resistance and type 2 diabetes in India and other Asian countries J Nutr 134 205-210

Yusuf S, Hawken S, Ônpuu S et al. (2004) Effect of potentially modifiable risk factors associated with myocardial infarction in 52 countries (the INTERHEART study): Case-control study The Lancet 364 937-952. 